\title{
Current Concepts of Snail Control
}

\author{
RF Sturrock \\ Department of Medical Parasitology, London School of Hygiene and Tropical Medicine, \\ Gower Strect, London WC1E 7HT, U.K.
}

\begin{abstract}
Schistosomiasis control was impossible without effective tools. Synthetic molluscicides developed in the 1950 s spearheaded community level control. Snail eradication proved impossible but repeated mollusciciding to manage natural snail populations could eliminate transmission. Escalating costs, logistical complexity, its labour-intensive nature and possible environmental effects caused some concern. The arrival of safe, effective, single-dose drugs in the 1970s offered an apparently better alternative but experience revealed the need for repeated treatments to minimise reinfection in programmes relying on drugs alone. Combining treatment with mollusciciding was more successful, but broke down if mollusciciding was withdrawn to save money. The provision of sanitation and safe water to prevent transmission is too expensive in poor rural areas where schistosomiasis is endemic; rendering ineffective public health education linked to primary health care. In the tropics, moreover, children (the key group in maintaining transmission) will always play in water. Large scale destruction of natural snail habitats remains impossibly expensive (although proper design could render many new man-made habitats unsuitable for snails). Neither biological control agents nor plant molluscicides have proved satisfactory alternatives to synthetic molluscicides. Biologists can develop effective strategies for using synthetic molluscicides in different epidemiological situations if only, like drugs, their price can be reduced.
\end{abstract}

Key words: schistosomiasis control - history - molluscicides - chemotherapy - biological control - strategies

This presentation considers snail control that is, or may be, used today for the control of schistosomiasis. It focuses primarily on Biomphalaria spp. that transmit Schistosoma mansoni, but where necessary I will use examples of Bulinus and Oncomelania spp. transmitting $S$. haematobium and $S$. japonicum respectively. First, though, I will summarise briefly what has been done in the past, what lessons have been learned, and how the views prevailing today have evolved. Without some historical perspective, it is easy to misunderstand current concepts of snail control. There is a real danger that workers planning control programmes today, whether against the snails or the parasites, will repeat the same mistakes as their forbcars - although cynics may say that this is the inevitable lesson of history!

In such a revue as this, it is very easy to resort to military metaphors, and I well remember Professor BG Peters, my PhD supervisor. abstracting a lengthy paper with the single sentence "Yet again Colonel $X$ likens the control of a parasitic disease to a military campaign". Nevertheless, military terminology is often convenient. Once Leiper (1915) had worked out the full life-cycle of $S$. mansoni, it was quite casy to identify its "wcak" links. Basically, there are four main targets: (i) kill the worms (in man); (ii) kill the aquatic snails (including those carrying intramolluscan parasites); (iii) stop people infecting snails (by contaminating water bodies); (iv) stop cercariae infecting man (keep people out of infested waters).

One must have the resources to achieve any combination of these four objectives. Money is obviously of paramount importance, and also trained personnel; but neither is of any value without appropriate weapons. Until well after the Second World War, those needed for objectives (i) and (ii) (antimonial drugs and inorganic molluscicides) were inadequate, and the costs of those for (iii) and (iv) (sanitation and safe water supplies which would have benefits far beyond the control of schistosomiasis), were (and remain) impossibly expensive, both in poor, rural areas and even some urban areas where schistosomiasis is endemic. Similarly, it would be prohibitively expensive and ecologically questionable to try to make extensive natural water bodies unsuitable for snails; but much could be done at the time of construction to prevent new water developments sprcading schistosomiasis, if only engineers would consult biologists early in the design stage.

Which brings me to two more military precepts: "know your enemy" and "time spent on reconnaissance (i.e. research) is seldom wasted". More conventionally, this means identifying the snails and 
understanding both their biology and their role in transmitting schistosomes, before planning any control programmes. The following examples illustrate three instances where these precepts were ignored.

Once it was realised that schistosomiasis on Egyptian and Sudanese irrigation schemes was transmitted by aquatic snails, the obvious way to kill the snails was periodically to dry out the canals. Leaving aside the many logistical and other problems this process actually involves in large-scale irrigation schemes, cultivating several different crops simultaneously, the strategy failed because it ignored two important biological features cvolved by Biomphalaria and Bulinus spp.: to survive in naturally unstable, aquatic habitats, both genera can aestivate (remain alive out of water) for cxtended periods; and both have high reproductive potentials, allowing survivors to explosively repopulate habitats as they refill with water. A second example is the Egypt-49 Scheme on the Nile Delta, where spring and autumn mollusciciding in the 1960s did not control schistosomiasis to the expected extent. The original strategy failed to appreciate the speed with which snails surviving the spring treatment recovered to allow the resumption of transmission before it was stopped by high summer temperatures (Gilles et al. 1973). The third example is the prolonged and expensive effort in the late 1960 s and 70 s to molluscicide the major canals of the Gezira irrigation scheme in the Sudan, first using gravity dispensers and then later by aerial spraying (Amin \& Fenwick 1977). The effect on transmission was minimal because by the time the treated water reached the main transmission sites at the tail ends of the most minor canals, molluscicide levels had fallen below concentrations toxic to the snails.

Some people negatively cite these examples as proof that snail control is uscless against schistosomiasis. I prefer to take a more positive view: they revealed the need for appropriate precontrol studies. Certainly we must never under estimate the role of the snails in maintaining schistosomiasis transmission. I will end this section on a more optimistic note. S. japonicum was virtually eliminated from Japan (WHO 1985, 1993) using molluscicides after lining irrigation canals with concretc. Similarly, filling snail infested canals with a mixture of chemicals and the spoil from newly-dug, parallel canals, controlled $S$. japonicum in extensive areas of China (Mao \& Shao 1982). Both of these programmes largely predated the appearance of modern drugs and molluscicides. However, I am getting ahead of myself.

\section{EVOLUTION OF SCHISTOSOMIASIS CONTROL SINCE 1950}

\section{Phase 1 - Snail control (1950-75)}

Synthetic molluscicides - In the late 1940s, the newly established World Health Organization recognised the need for weapons to fight discases. The available drugs and insecticides were thought adequate rapidly to eradicate malaria, but there were no such effective drugs or molluscicides for schistosomiasis. WHO collaborated with other organizations and industry in a massive research programme to remedy this deficiency. Quite by chance, the first fruits in the late 1950s and early 1960s were the molluscicides: NaPCP (sodium pentachlorophenate), then niclosamide $(2 ', 5-$ dichloro -4 - nitrosalicylanilide) and finally Frescon $^{(8)}$ (N-tritylmorpholine). Thereafter, the work on synthetic molluscicides gradually declined and, despite promising experimental results with certain organotins, nicotinanalide and its $3^{\prime}$ - and 4 -chloro analogues and, in Japan, compound B-2 (sodium 2, 5 dichloro-4-bromophenol), no new synthetic compounds have been developed for commercial production, apart from Yuramin ${ }^{\mathbb{R}}(3,5-$ dibromo 4 hydroxy -4 - nitroazo benzene) produced in Japan to replace NaPCP. Frescon and Yuramin production has now ceased, but NaPCP is still used in some parts of China (Webbe 1991). Niclosamide proved to be the most versatile and effective of the commercially produced compounds and is now the molluscicide of choice. It is produced commercially as a wettable powder, with between 50 and $70 \%$ a.i., in Germany (Bayluscide ${ }^{(1)}$ ). Egypt (Mollotox ${ }^{\circledR}$ ), Korea and the Peoples Republic of China.

Plant molluscicides - The use of plant products in the battle against tropical diseases is well known, e.g. quinine and artemesin in malaria control; pyrethum for controlling numerous insect pests and vectors. Not surprisingly, there have from time to time been reports of plants with molluscicidal properties (see Mott 1987 for extensive reviews). Examples are Artemisia maritima, Schwartzia madagascarensis, Polygonum senegalensis, Euphorbia elegens, Balanites aeguptiaca and, perhaps the best documented of all, Phytolacca dodencandra (Endod). Infusions and $\mathrm{cx}$ tracts of different parts of these plants, collected at various stages of their development, undoubtedly contain chemicals that are molluscicidal in the laboratory, and some have even been tested with mixed success in the field.

The main justification for studying plant molluscicides is that, because they may be grown in countries where schistosomiasis is endemic, their substitution for synthetic chemicals will conserve 
precious foreign exchange. However, there are two very real problems in developing them. The first is toxicity. Many were originally considered becausc they were known to kill fish and other animals. Since they will be applied in endemic areas to water which is often the only supply for humans and their domestic animals, preliminary and expensive testing is necessary to confirm their safety before approving their widcspread use. Secondly, although many plants grow in small numbers in the wild. the large-scale cultivation of, for example, Endod. has proved extremely difficult (Lugt 1981). The provision of adequate amounts for continued. routine large-scale use has rarely, if ever, been achieved. This is not to say that we should not continue to search for plant molluscicides, but their development from the detection of activity to full production is no casier than for a synthetic molluscicide, especially today when there is a far greater awareness of both toxicological and environmental risks.

Biological control - Predators, pathogens and competitors of snails - As with plant molluscicides, researchers have tried to find biological control agents for snails (Hairston et al. 1975, McCullough 1981, WHO 1984. Madsen 1990). Some proposed agents, such as birds, turtles, fish and crayfish, have been observed eating snails in the field. Many more, such as leaches, nematodes, rotifers and ostracods, caused extensive mortality when they accidentally infested laboratory snail colonies. Whilc most undoubtedly can exterminate snails in the laboratory, such predators are rarely effective in the field. Snails form only part of their diet and they turn to other food sources when snail numbers drop. So they eat snails only when they are abundant and their main effect is to limit the size of cstablished snail populations. In stable habitats this may lead to alternating predator-prey cycles, but rarely to the elimination of the snails.

Theoretically, obligate snail pathogens are likely to be the most effective biological control agents (WHO 1984). Unfortunately, once all the snails have died so, too, will the pathogens. They would have to be reintroduced if the site were reinvaded by the snails. Microsporidia are the only organisms I know of that might be used in this role. They have been so difficult to maintain in the laboratory that it is hard to visualise their use in routine control (Michelson 1963). Facultative pathogens face the same problems as predators: they may limit but will rarely eradicate snails.

So far, the most promising control agents have been competitor snails, and there have been scveral documented examples of the 'natural' displaccment of snails transmitting schistosomes in the field (Ferguson 1972, Barbosa 1973, 1987, MicheIson \& Dubois 1979, Pointicr \& McCullough
1989). It is not always easy to dissociate such phenomena from long-term. environmental changes, sometimes precipitated by human activities. If the effect is due solely to competition, then the competitors either modify the snail habitats by destroying aquatic vegetation which provides food, refuges and egg laying sites for the target snail (c.g. Marissa cornuariatus. which may also accidentally eat the eggs and hatchlings of the target snails); or they deplete essential ions (e.g. possibly Thiara spp.), or they compete more vigorously for limited resources (c.g. Pomacea spp., Helisoma spp., and B. straminea). However, aquatic snails can survive a wide-range of physico-chemical conditions. If the optimal combination of conditions differs for the competitor and target snails, the two species will eventually segregate into different niches within the same habitat, with competition confined to overlapping areas sub-optimal for both specics. The best competitors will be those most closely related to the target species, sharing virtually identical requirements.

B. stramine a displacing B. glabrata in the Caribbean and parts of northeasiern Brazil is especially interesting: the greater fecundity of $B$. straminea gives it a competitive advantagc over $B$. glabrata. Caribbean and some Brazilian strains of $B$. straminea are refractory to the local $S$. mansoni. Alas, susceptible strains of $B$. straminea also occur in Brasil, and there is a risk that an initially resistant strain could become susceptible to the local $S$. mansoni. The same applies to resistant strains of other Biomphalaria and Oncomelania spp. (Chu et al. 1982). Much more needs to be understood about the processes determining resistance and susceptibility of snails to schistosomes, possibly at the molecular level (Johnston et al. 1993), before seriously considering apparently 'resistant' strains for use as biological control agents.

It is sometimes argued that exotic species (i.e. species introduced from other geographical areas) will have a greater chance of success. However, this approach is not without its dangers and using exotic species is generally discouraged, unless proper steps have becn taken to ensure that they will not pose other environmental and health problems (WHO 1984, 1993).

Hyperparasites - trematode antagonists - A considerable amount of research has been conducted on the use of hyperparasites (other trematode spccics whose redia actively seck and devour larval schistosomes within the snail). Most of the studies used echinostomes in the laboratory, although there have been some expcriments in simulated field sites in endemic areas. However, there have been very few ficld studies to assess this impact on schistosome transmission. In Thailand, adding 600 million eggs to a pond over seven mon- 
ths never produced infection rates above $50 \%$ of E. malayensis in Indoplanorbis exustus, i.e. insufficient to stop $S$. spindale transmission (Lic et al. 1974).

As with competitor snails, the use of exotic parasites is not generally encouraged, but augmenting transmission of endemic parasites does not seem to be a promising alternative. On the Caribbean island of St Lucia. the prevalence of $B$. glabrata infected with Ribeiroia marini, an excellent hyperparasite in laboratory studics (Huizinga 1973), often greatly exceeded that of $S$. mansoni, but at a time when high prevalences of $S$. mansoni. persisted in the human population (Basch \& Sturrock 1969).

There may even be dangers in using hyperparasites. Depending on the relative timing of infection. their presence may sometimes enhance the susceptibility of snails to schistosomes, rendering resistant species open to infection (Lie 1982). A polyploid variant of Bulinus tropicus, a snail normally totally resistant to all schistosomes. was found in Kenya naturally infected with the cattle schistosome. S. bovis, but only in mixed infections with paramphistomes (Southgate et al. 1986).

Attractive, then, as the idea may appear of setting parasites to fight one another, there is little evidence so far that it will work. and it may even involve some unexpected dangers.

The use of synthetic molluscicides - Changing objectives - Molluscicides spearheaded the attack on schistosomiasis at a community level from the $1950 \mathrm{~s}$ well into the $1970 \mathrm{~s}$. There was, though, a progressive shift from the initial objective of eradication to suppression of snail populations. This shift paralleled research on snail population dynamics to allow mollusciciding to capitalise on the natural scasonality in snail numbers. This rescarch also revealed an cven more restricted transmission season in many areas. A logical development was to manage snail populations with molluscicides to suppress transmission, rather than to eradicate the snails (Sturrock 1989).

Overall delivery strategy: area-wide versus focal control - Adequate precontrol studies are essential to define the basic transmission patterns in any given area. These studies should cover at least one. and better two, seasonal cycles. Based on their findings, rational decisions can be taken on the subsequent strategy to be adopted for snail and schistosome transmission control. There has been some controversy about the relative merits of areawide (sometimes referred to incorrectly as blanket) treatment versus focal mollusciciding (Webbe 1991).

For denscly populated, man-made habitats, such as irrigation schemes, and some natural water sheds with extensive and complicated water bodies, it is usually considered that a relatively small number of well-trained and supervised staff are best used systematically to molluscicide all potential transmission sites, in effect all water bodies. Particularly on extensive irrigation schemes, systematic mollusciciding at predefined intcrvals must be integrated with controlled water management and sound synoptic data (i.e. distribution information, rotations and discharges) to insure proper molluscicide coverage. This approach has high chemical costs and exposes all water bodies to adverse cnvironmental effects, if any; but it does not require large surveillance teams or decisions on whether or not to apply treatment.

In contrast. focal mollusciciding relies on accurate identification of transmission sites, and a system of regular surveillance to detect snails and allow rational decisions on whether or not to treat them. Molluscicide costs and any environmental damage will be minimised, but the approach requires well trained and supervised surveillance teams, capable of making the necessary decisions. In many rural areas with relatively simple water systems, there is no reason why this approach should not succeed. In particular, it is eminently suitable for integration into Primary Health Care programmes involving the lowest echelons of the conventional health services collaborating with members of the local community. Both methods, area-wide or focal, were later used to compliment population chemotherapy.

\section{Phase 2 - Drug control (1975 - present)}

The drugs - This is not the place for an extensive description of the new generation of schistosomicidal drugs (see Davis 1993). However, because they have profoundly altered attitudes to the use of molluscicides, we should note three drugs, in particular, that were developed as the programme initiated by WHO bore fruit. The organophosphorus drug metrifonatc is safe. cheap and effective against $S$. haematobium, but has the disadvantage that it requires three doses given at fortnightly intervals. Oxamniquine is a safe, single dose drug effective against $S$. mansoni. The last of the trio, praziquantel. a safe, single dose drug effective against all schistosomes infecting man, came into general use in the early $1980 \mathrm{~s}$.

Programmes using drugs alone - WHO (1980) had already warned that schistosome control programmes should not rely on one, but should incorporate a range. of control measures. Despite this advice, some programmes have used drugs alone. mainly because of limited resources, but also to allow uncomplicated comparisons of different drugs (King et al. 1988) or delivery stratcgies (Butterworth et al. 1991). In other cases, chemotherapy was incorporated or ethically neccssary in studies 
of other aspects of schistosomiasis, e.g. treatmentreinfection studies on immune phenomena with the long-term goal of developing vaccines (Butterworth et al. 1994).

In Zanzibar, a pilot chemotherapy project reduced overall prevalence and pathology due to $S$. haematobium, judged by a decline in haematuria (Savioli et al. 1989). Since then, an expanded primary health care programme is producing a stcady decline in haematuria, but transmission continucs (WHO 1993). Much the same was found in a comparison of the efficacy of metrifonate and praziquantcl against $S$. haematobium on the coast of Kenya (King et al. 1989, Sturrock et al. 1990). In a series of studies of $S$. mansoni on the Kenyan plateau, single and multiple chemotherapy reduced prevalence and intensity of infection for varying periods, depending on the local interısity and transmission patterns. Repeated treatments were essential to maintain any overall reduction in schistosomal pathology and. cven after as many as six treatments, severe pathology persisted in some patients. Transmission. though probably reduced, continued (Butterworth et al. 1989, 1994).

Integrated programmes - In the mid 1970s, using hycanthone (a forerunner of today's single dose drugs) on the West Indian island of St Lucia. several successive community chemotherapy programmes eventually reduced prevalence and intensity, but failed to stop transmission and reinfection. Focal mollusciciding was then introduced and transmission was held to insignificant levels for several years (Jordan 1985).

In Brazil, the 'vertical', national PECE programme was initiated in the mid 1970)s using oxamniquine as the primary weapon for mass or selective population chemotherapy which varied according to the endemicity found in pilot surveys in each community. Additional control measures were used as appropriate (Almcida Machado 1982). Such an extensive programme covering 10 million or so pcople cannot be summarised in a few sentences but the recently published findings from the town of Peri-Peri are illuminating (Coura Filho et al. 1992. Lima Costa et al. 1993). Between 1974 and 1983, annual community treatments of all cases detected resulted in a steady if somewhat crratic drop in prevalence and incidence of $S$. mansoni. accompanied by a decline in the prevalence of advanced schistosomal discase. Supplementary measures included improvements in water supplies and sanitation which were available to $90 \%$ or more of the inhabitants by 1984, and molluscicides used in a surveillance-treatment programme covering known transmission sites. Nevertheless, transmission was still aclive when the main PECE programme ceased in 1983. The control programme continued in what was, in fact. a Primary
Health Care programme, executed by the local health authorities advised by 'experts' from the local Oswaldo Cruz Institute. The various indices of schistosomiasis control continued to decline but, despite this success, infected snails were still present in 1987 indicating continued transmission. Despite similar successes elsewhere in Brasil, cases with heavy pathology continue to be reported (Domingues et al. 1993)

In Egypt, a vertical national schistosomiasis programme was set up in 1977 to control the transmission of $S$. haematobium in much of middle Egypt (Mobarak 1982). Based on the lessons learned from earlier Egyptian bilharzia control campaigns, this programme combined regular, population based chemotherapy with systematic, area-wide mollusciciding to minimise transmission. Between 1977 and 1985, the overall prevalence of $S$. haematobium dropped stcadily from over $30 \%$ to below $9 \%$ (Anon 1987). Then, an attempt was made to reducc costs by switching from area-wide to focal mollusciciding (Webbe \& El Hak 1990). Over the following five years, prevalence stabilised but reinfection rates in children indicated substantial continuing transmission (Webbe 1991).

These examples give apparently conflicting cvidence about the value of snail control as an adjunct to chemotherapy against schistosomiasis. The results from St Lucia and Egypt support its value, as 100 , do results from other programmes in north Africa, islands in the Indian Ocean, and from the Middle East (WHO 1985, 1993). The findings from Brasil are equivocal as far as snail control is concerned, and. for that matter, the provision of water and sanitation. Prolonged, systematic chemotherapy and mollusciciding eventually reduced schistosomiasis to levels of minimal public health significance. but would the process have taken longer without the supplementary control measures?

To summarise, the accumulated weight of evidence suggests that drugs alone, applied repeatedly over an extended time period, can contain or minimise the amount of schistosomal pathology. Rarely, though. will this inherently expensive process halt transmission, and when treatment is stopped. all the ground gained will eventually be lost. Molluscicides represent an important, well tried and effective tool to supplement chemotherapy (Sturrock 1989). They can also help to maximise its cost-cffectiveness

\section{INTEGRATED DRUG AND MOLLUSCICIDAL CONTROL}

General concepts - We are all familiar with the basic schistosome life-cycle but its quantitative aspects are often overlooked. Most of the millions of eggs produced by the adult worms in man 
are wasted, remaining trapped in man's tissues or producing miracidia which fail to find a snail. However, the few successful miracidia multiply in an amplification phase in the snail to produce cnough cercariac to reach man. Again, very few succeed. A conservative estimate from St Lucian data suggested that a single pair of worms could produce 30 billion offspring, but only two, one male and one female, need complete the cycle to maintain a stable parasite population. Note. too. that drugs used to kill adult worms do not affect the parasites already in the snails, and that the amplification process permits successful offspring of worms surviving treatment to multiply rapidly and maintain transmission. On the other hand. although it can stop transmission, effective mollusciciding will have no immediate effect on the adult worm population: the inevitable reappearance of snails will soon be followed by a resumption of transmission.

Neither method alone, even applied for years or possibly decades, eliminates transmission. A combination of the two methods offers two advantages, especially in areas of seasonal transmission. The optimum time for chemotherapy is when the snail populations are absent and there is no risk of reinfection. This window of opportunity is often quite short, especially when the prepatent periods of infection in both snails and man are taken into account. The latter delays diagnosis of new infections by 6 to 8 weeks using parasitological methods (egg detection), or by 4 wecks using the antigen detection techniques currently being developed. Unfortunately, in the real world it is hard to predict precisely when transmission seasons will start or end. Accurate snail survejllance by field teams is possible, if costly, but will work only on a relatively small scale when the logistics of rapidly mounting a drug treatment campaign will be feasible. A simpler alternative would be to mount a mollusciciding programme immediately before a preplanned chemotherapy campaign to avoid immediate reinfection.

It is, of course, naive to hope that a single, combined molluscicide and drug campaign in the "attack' phase of a control programme will eradicate schistosomiasis from a community. The concept of subsequent 'consolidation' and 'maintenance' phases lasting many years is now well accepted (WHO 1985, 1993). In recent years this has usually been interpreted as repeated (targeted) chemotherapy, plus long term investment in sanitation and/or water supplies, coupled with health education to improve community participation in primary health care programmes.

The weakness of this strategy is that these supplementary control measures have least impact among young children; probably the most important group maintaining transmission. In tropical countries, children will invariably continue to play in and contaminate water bodies, irrespective of any improved sanitation and water supplies. By the time they are old enough to understand health education designed to change their behaviour, they will already have fulfilled their role in maintaining schistosomiasis in the community. Transmission control independent of childrens' behaviour is required between annual chemotherapy campaigns. Molluscicides provide an obvious and proven solution in many nural and urban situations.

This brings us to the second benefit given by molluscicides. By minimising transmission after chemotherapy, they may allow the interval between successive chemotherapy campaigns to be cxtended. It will reduce how often the local population is 'disturbed' - compliance is, in general, inversely related to how often people are subjected to examination and treatment.

(osts - Accurate costing of control programmes is not easy to obtain. People quoting the apparently high costs recorded for the St Lucia Project (Jordan 1985) often forget that it was essentially a research programme. More realistic costs for a fully operational programme are given by Webbe (1991), and these show that mollusciciding was not excessively expensive in a large, densely populated irrigation schemes. But can these costs be translated to small, nural or urban situations?

The precise costing of combined treatments can only be determined under operational conditions. However, a hypothetical case illustrates the potential savings in arcas with seasonal transmission. In a small community of about 1000 people, annual mass chemotherapy (to avoid diagnostic costs) for 6 years at $\$ 4$ per person for the entire population would cost $\$ 24,000$ for drugs alone, excluding additional delivery costs. Targeting treatment immediately requires diagnostic costs which effectively cancel out most potential savings from reduced drug usage. Inevitably, during such a programme, community compliance will diminish, increasing the risk of reinfection.

In the same community, a few small streams could be treated two or three times a year with no more than $30 \mathrm{~kg}$ of Bayluscide costing about US $\$ 1200$ per year ( $\$ 40$ per $\mathrm{kg}$ at present prices). To this must be added labour costs and that of mollusciciding dispensers. Labour costs would be trivial - 12 man days a year. Regular surveillance of the streams would require another 40 to 60 man days a year. This labour could quite easily be recruited and trained locally within a primary health care programme. Over 6 ycars, molluscicide would cost about $\$ 7,000$.

For a six year programme combining annual mollusciciding and mass treatment at three yearly intervals, the basic cost would be $\$ 15,200$, i.e. 
$\$ 7,200$ for molluscicides and $\$ 8,000$ for drugs. This gives both a $30 \%$ cost reduction, compared with the basic drug cost of annual chemotherapy. and also the added advantage of addressing the recurrent problem of reinfection.

These hypothetical figures are obviously subject to correction, and any substantial changes in the assumptions will lead to different conclusions. For example, donor agencies are actively trying to reduce the price of drugs. If they were available at less than $\$ 1$ per treatment, or even free, the costing picture could change dramatically in favour of repeated chemotherapy alone, but this would then leave the problem of reinfection untackled. Is it not time that the donor agencies made similar efforts to cut the cost of niclosamide?

Operational requirements - For such an approach to work, there are several prerequisites. There must be a cadre of competent ficld biologists to undertake precontrol studies and participate in the design and execution phases of any control programmes. including the training and supervision of locally recruited field workers. Surely training suitable biologists is not impossible? It is also critical to ensure an uninterrupted supply of necessary drugs, molluscicides and equipment, possibly by bulk purchase through a central, national agency, once a control programme has been agrecd.

Possible problems - Toxicitv - It is likely that there may be some resistance to the use of niclosamide because of supposed, unwanted environmental effects. Niclosamide is biodegradable and soon disappears from treated field sites. There is no doubt that it kills fish, amphibians and various invertebrates, but these generally mobile species have great powers of dispersion and soon return from untreated sites. Fish mortalities can even be turned to advantage as the fish may be safely eaten: advance warning of mollusciciding can provide the community with a much appreciated fish supper! In particular, it should be stressed that niclosamide is not toxic to man, domestic animals or crops which may come into contact with treated water.

Formulations - An emulsifiable concentrate of niclosamide was produced in the 1970 s but it is now available only as a wettable powder. Alas, there is little likelihood of other formulations being developed commercially, but various granules can be made locally from the wettable powder to treat certain difficult habitats. Molluscicide application relies on equipment, devcloped primarily for agricultural use, that may require some adaptation to use in aquatic habitats.

Resistance - A perennial worry is that snails may eventually develop resistance to molluscicides. So far, there has been no reliably documented case of this occurring in the laboratory or after years of continuous use in the ficld.

\section{CONCLUSION}

Webbe (1991), commenting on some current misapprehensions about molluscicides, recommended that "The Expcrt Committee [of WHO] should give the lie to these fallacious beliefs, in recognising that mollusciciding is an important adjunct to chemotherapy and other methods in many endemic situations, if cost-effective, lasting control is to be achieved." I am happy to report at least two positive steps to implement his recommendation: WHO has published a handbook on the use of molluscicides (McCullough 1992); and they still recommend snail control in the most recent report of the Expert Committee on Schistosomiasis (WHO 1993).

\section{REFERENCES}

Almeida Machado P 1982. The Brazilian program for schistosomiasis control, 1975-1979. Am J Trop Med Hyg 31: 76-86.

Amin MA, Fenwick A 1977. The development of an annual regimen for blanket snail control on the $\mathrm{Ge}$ zira Irrigated Area of the Sudan. Ann Trop Med Parasitol 71: 205-212

Anon 1987. Report of an independent evaluation mission on the national control programme in Egypt, 1985. Trans R Soc Trop Med Hyg 81: suppl 1-57.

Barbosa FS 1973. Possible competitive displacement and evidence of hybridization between two Braziljan species of planorbid snails. Malacologia 14: 401408.

Barbosa FS 1987. Competitive displacement of Biom phalaria glabrata by Biomphalaria straminea. Mem Inst Oswaldo Cruz 80 (Suppl IV): 139-141.

Basch PF, Sturrock RF 1969. I ife history of Ribeiroia marini (Faust and Hoffman, 1934) sp.n. (Trematoda: Cathaemasiidae), J Parasitol 55: 1180-1184.

Butterworth $\mathrm{AE}$, Curry AJ, Dunne IDW, Fulford AJC, Kimani G, Kariuki CK, Klumpp R, Koech D, Mbugua G. Ouma JH, Roberts M, Thiongo FW, Capron A, Sturrock RF 1994. Immunity and morbidity in human schistosomiasis mansoni. Trop Geogr Med 46: 197-208.

Butterworth AE, Sturrock RF, Ouma JH, Mbugua G, Fulford AJC, Koech D 1991. Comparison of different chemotherapy strategies against Schistosoma mansoni in Machakos District, Kenya. Parasitology 103: 339-355.

Chu JG, Ong SJ, Yu JC, Kao CY, Lijima T 1982. Susceptibility of Oncomelaniahupensis formosana recombinants and hybrids with $O$. hupensis nosophora to infections with Schistosoma japonicum. JParasitology 11: 391-397.

Coura Filho P, Mendes NM, Souza CP, Pereira JP 1992. The prolonged use of niclosamide as a molluscicide for the control of Schistosoma mansoni. Rev Inst Med Trop Sao Paulo 34: 427-431

Davis A 1993. Antischistosome drugs and clinical practice, p. 367-404. In P Jordan, G Webbe, RF Sturrock 
Human Schistosomiasis. CAB International, Wallingford.

Domingues I.C, hima ARF, Dias I IS, I cão GC, Coutinho $\Lambda$ 1993. An ultrasonographic study of liver fibrosis in patients infected with Schistosoma mansoni in north-east Brazil. Trans R Soc Trop Med Hyg 87: 555-558.

Ferguson F 1972. Biological control of schistosomiasis snails, p. 85-92. In J Miller Schistosomiasis: Proceedings of a Symposium on the Future of Schistosomiasis Control. Tulane University, Louisiana.

Gilles HM, Taki AAA, Soussa SA, Samaan SA, Soliman SS, Hassan A, Barbosa FS 1973. Results of a seven year snail control project on the endemicity of Schistosoma haematobium infection in Egypt. Ann Trop Med Parasitol 67: 45-65.

Hairston NG, Wurzinger KH, Burch JB 1975. Non chemical methods of snail control. WHO/VBC/75, 873. WHO, Geneva, $30 \mathrm{pp}$.

Huizinga HW 1973. Ribeiroia marini: pathogenesis and larval antagonism in the snail Biomphalaria glabrata. Exp Parasitol 33: 351-364.

Johnston DA, Dias Neto E, Simpson AJG, Rollinson D 1993. Opening the can of worms: molecular analysis of schistosome populations. Parasitology Today 9. $286-291$.

Jordan P 1985. Schistosomiasis: the St Lucia Project. Cambridge University Press, Cambridge. $442 \mathrm{pp}$.

King $\mathrm{CH}$, Lombardi $\mathrm{G}$, Lombardi $\mathrm{C}$, Greenblatt R, Hodder $\mathrm{S}$, Kinyanjui $\mathrm{H}$, Ouma $\mathrm{H}$. Odiambo $\mathrm{O}$, Bryan $\mathrm{PJ}$, Muruka J, Magak P, Weinert D, Mackay W, Ranshoff D, Houser H, Koech D, Siongok TK, Mahmoud AAF 1988. Chemotherapy-based control of schistosomiasis haematobia. I. Metrifonate versus praziquantel in control of intensity and prevalence of infection. Amer $J$ Trop Med Hyg 39: 295-305.

Leiper RT 1915. Observations on the mode of spread and prevention of vesical and intestinal schistosomiasis in Egypt, with additions to 1916. Proc $R$ Soc Med 9: 145-172.

Lie KJ 1982. Survival of Schistosoma mansoni and other trematode larvae in the snail Biomphalaria glabrata. A discussion of the interface theory. Trop Geogr Med 34: 111-122.

Lie KJ, Schneider SR, Sommani S, Lanza GR, Impand P 1974. Biological control by trematode antagonism: II. Failure to control Schistosoma spindale in North East Thailand. SE Asian J Trop Med Publ HIth 5: 46-59.

Lima Costa MMF, Rocha RS, Coura Filho P, Katz N 1993. A 13-year follow-up of treatment and snail control in an area endemic for Schistosoma mansoni in Brasil: incidence of infection and reinfection. Bull Wld Hlth Org 71: 197-205.

Lugt CB 1981. Phytolacca dodecandra berries as a means of controlling bilharzia transmitting snails. Litho Printer, Addis Ababa, 61 pp.

Madsen H 1990. Biological methods for the control of freshwater snails. Parasitology Today, 6: 237-241.

Mao S-P, Shao BR 1982. Schistosomiasis control in the People's Republic of China. Amer J Trop Med Hyg
31: $92-99$

McCullough FS 1981. Biological control of snail intermediate hosts of human Schistosoma spp: a review of its present status and future prospects. Acta Trop 30: 5-13.

McCullough FS 1993. The role of mollusciciding in schistosomiasis control. WHO/92.107.WHO, Geneva, $35 \mathrm{pp}$

Michelson EH 1963. Plistophora husseyi sp.n., a microsporidian parasite of aquatic pulmonate snails. J Insect Path 5: 28-38.

Michelson EH, Dubois L 1979. Competitive interaction between two snail hosts of Schistosoma mansani: laboratory studies on Biomphalaria glabrata and Biomphalaria straminea. Rev Inst Med Trop São Paulo, 21: 246-253.

Mobarak AB 1982. The schistosomiasis problem in Egypt. Amer J Trop Med IJyg 31: 89-91.

Mot KE 1987. Plant molluscicides. John Wiley \& Son Ltd., Chichester. $326 \mathrm{pp}$.

Pointier J-P, McCullough FS 1989. Biological control of the snail hosts of Schistosoma mansoni in the Caribbean area using Thiara spp. Acta Trop 46: 147155

Savioli L, Dixon H, Kisumko UM, Mott KE 1989. Control of morbidity due to Schistosoma haematobium on Pemba Island: selective population chemotherapy of schoolchildren with haematuria to identify highrisk localities. Trans $R$ Soc Trop Med Hyg 83: 805810 .

Southgate VR, Brown DS, Rollinson D, Ross GC, Knowles RJ 1986. Bulinus tropicus from entral Kenya acting as a host for Schistosoma bovis. $Z$ Parasitenkunde 71: 61-69.

Sturrock RF 1989. Schistosomiasis: complimentary snail control in chemotherapeutic based control programmes. p. 51 - 60. In MJ Miller \& FS Love Parasitic diseases: treatment and control. CRC Press, Baton Rouge.

Sturrock RF, Kinanjui H, Thiongo FW, Tosha S, Ouma JH, King CII, Koech D, Siongok TK, Mahmoud AAF 1990. Chemotherapy-based control of schistosomiasis haematobia. 3. Snail studies monitoring the effect of chemotherapy on transmission in the Msambweni area, Kenya. Trans $R$ Soc Trop Med IIyg 84: $257-261$.

Webbe G 1991. Current concepts of snail control. SCH/ EC/91/WP.17. WHO, Geneva. 4 pp.

Webbe G, El Hak S 1990. Progress in the control of schistosomiasis in Igypt, 1985 - 1988. Trans R Soc Trop Med Hyg 84: 394-400.

WHO 1980. Hidemiology and control of schistosomiasis. WHO Tech Rept Ser 643, WHO, Geneva. $63 \mathrm{pp}$.

WHO 1984. Report of an informal consultation on the biological control of snail intermediate hosts. TDR/ BCV-SCH/SIH/84.3. WHO, Geneva. $39 \mathrm{pp}$.

WHO 1985. The control of Schistosomiasis. WHO Tech Rept Ser 728, WHO, Geneva. 113 pp.

WHO 1993. The control of Schistosomiasis. WHO Tech Rept Ser 830 , WHO, Geneva. 86 pp. 